\title{
Distribution and Abundance of Diurnal Mammals, Especially Monkeys, at Kasoje, Mahale Mountains, Tanzania
}

\author{
Shigeo Uehara ${ }^{1}$ and Hiroshi Ihobe ${ }^{2}$ \\ 1 Institute of Natural History, Sapporo University, \\ 3-7-3-1 Nishioka, Toyohira-ku, Sapporo 062-8520 \\ 2 Laboratory of Human Evolution Studies, Department of Zoology, \\ Faculty of Science, Kyoto University, Sakyo-ku, Kyoto 606-8502
}

(Accepted November 17, 1998)

\begin{abstract}
Censusing was done by direct observation along three survey routes to estimate the distribution and abundance of medium- and large-sized diurnal mammals in the Kasoje area of the Mahale Mountains National Park, western Tanzania between 1995 and 1996. The census area is located within the home range of M Group chimpanzees who have been observed to consume at least 14 species of sympatric mammals. The vegetation along the three census routes was divided into two types of habitat (forest vs. woodland); as a result, six census subunits were distinguished. Preference of habitat by eight species of mammals red-tailed monkey, blue monkey, yellow baboon, red colobus monkey, bushbuck, blue duiker, warthog, and forest squirrels - has been suggested and their group and/or individual densities have been estimated in at least one census subunit. In 1974, most villagers moved out of the Kasoje area following a government edict and the wild animal population in general appears to have increased in number since then. However, expansion or contraction in distribution of three species of mammals at Kasoje since the 1970s differs from species to species: yellow baboons and warthogs have apparently expanded their ranges while vervet monkeys seem to have contracted theirs. The abundance of red colobus monkeys appears to correspond with the high frequency of colobus hunting by the chimpanzees. However, it should be explained in the future why the second most abundant red-tailed monkeys, another resident arboreal species, have been eaten only infrequently by them. Further accumulation of observations on actual encounters between the chimpanzees and their potential prey is necessary.
\end{abstract}

Keywords: Mahale Mountains, route census, diurnal mammal, density, chimpanzee

\section{Introduction}

Long-term socio-ecological investigation of chimpanzees (Pan troglodytes) and their habitat in the Mahale Mountains National Park, western Tanzania has been carried out 
for more than three decades since 1965 (Nishida, 1968, 1996). Although faunal and floral data have been accumulated during these studies (Itani, 1977; Anon., 1980; Nishida and Uehara, 1981, 1983; Takada and Uehara, 1987; Okada and others, 1988; Nishida, 1990; Sasaki, unpublished data), there are few quantitative data on sympatric species of animals, except for monkeys (Nishida, 1969, 1972; Hasegawa and others, 1980; Takahata, 1981; Ihobe, unpublished data). The present study sought to census the medium- and large-sized diurnal mammals at Mahale in order to help fill this gap, as such basic information is necessary for park management planning.

Collectively, the chimpanzees of $\mathrm{K}$ and $\mathrm{M}$ Groups at Mahale are known to eat 17 species of mammals, at least 14 species of which have been consumed by the chimpanzees of $\mathrm{M}$ Group (Uehara and others, 1992; Nakamura, 1997). Thus, the present goal is to estimate the abundance of prey mammals eaten by the chimpanzees and to investigate the influence of the prey availability on the prey selectivity in the chimpanzee hunting. Since red colobus monkeys (Colobus badius) are reported to be the most frequently eaten animals by $\mathrm{M}$ Group chimpanzees, followed by blue duikers (Cephalophus monticola) (Takahata and others, 1984; Uehara and others, 1992; Hosaka, 1995), at least they are expected to be abundant. Prey selectivity in the hunting of Mahale chimpanzees needs to be evaluated in relation to the availability of their prey (Nishida and Uehara, 1983; Uehara, 1997). Detailed information on the abundance of potential prey has not been systematically collected at any site in Africa where the hunting behavior of chimpanzees has been intensively studied, that is, Gombe in Tanzania and Taï in Ivory Coast (Gombe: Goodall, 1986; Wrangham and Bergmann Riss, 1990; Stanford and others, 1994; Tai: Boesch and Boesch, 1989), except for the densities of sympatric red colobus monkeys at Gombe and Taï and Diana monkeys (Cercopithecus diana) at Taï (Gombe: Stanford, 1995; Taï: Holenweg and others, 1996; Noë and Bshary, 1997).

\section{Methods}

The census was done on the western slope of the northern part of the Mahale Mountains along the eastern shore of Lake Tanganyika in the Kasoje area. The study covers an area of about $9 \mathrm{~km}^{2}$ within the $30 \mathrm{~km}^{2}$ home range of $\mathrm{M}$ Group chimpanzees $\left(6^{\circ} 05^{\prime}-10^{\prime} \mathrm{S}, 29^{\circ}\right.$ $44^{\prime}-45^{\prime}$ E: Figure 1) between August and December, 1995 (Period I by H. I.) and between October and December, 1996 (Period II by S. U.). A single rainy season usually starts in October at Mahale, which was not exceptional in both years. According to Nishida and others (1979), about $80 \%$ of the chimpanzee study site in the 1970s including the home ranges of both $\mathrm{K}$ and $\mathrm{M}$ Groups was covered with vegetation of forest types (semideciduous) and the remaining $20 \%$ with vegetation of woodland types (deciduous). Turner (unpublished data) estimates that in 1994 total forest cover (= lowland forest plus abandoned farmland) was about $79 \%$ in her study site of approximately $20 \mathrm{~km}^{2}$ in which the present study area is included. Chimpanzees use both types of vegetation, although marked seasonal or inter-annual shifts occur in their habitat utilization patterns (for example, Nishida, 1974). 


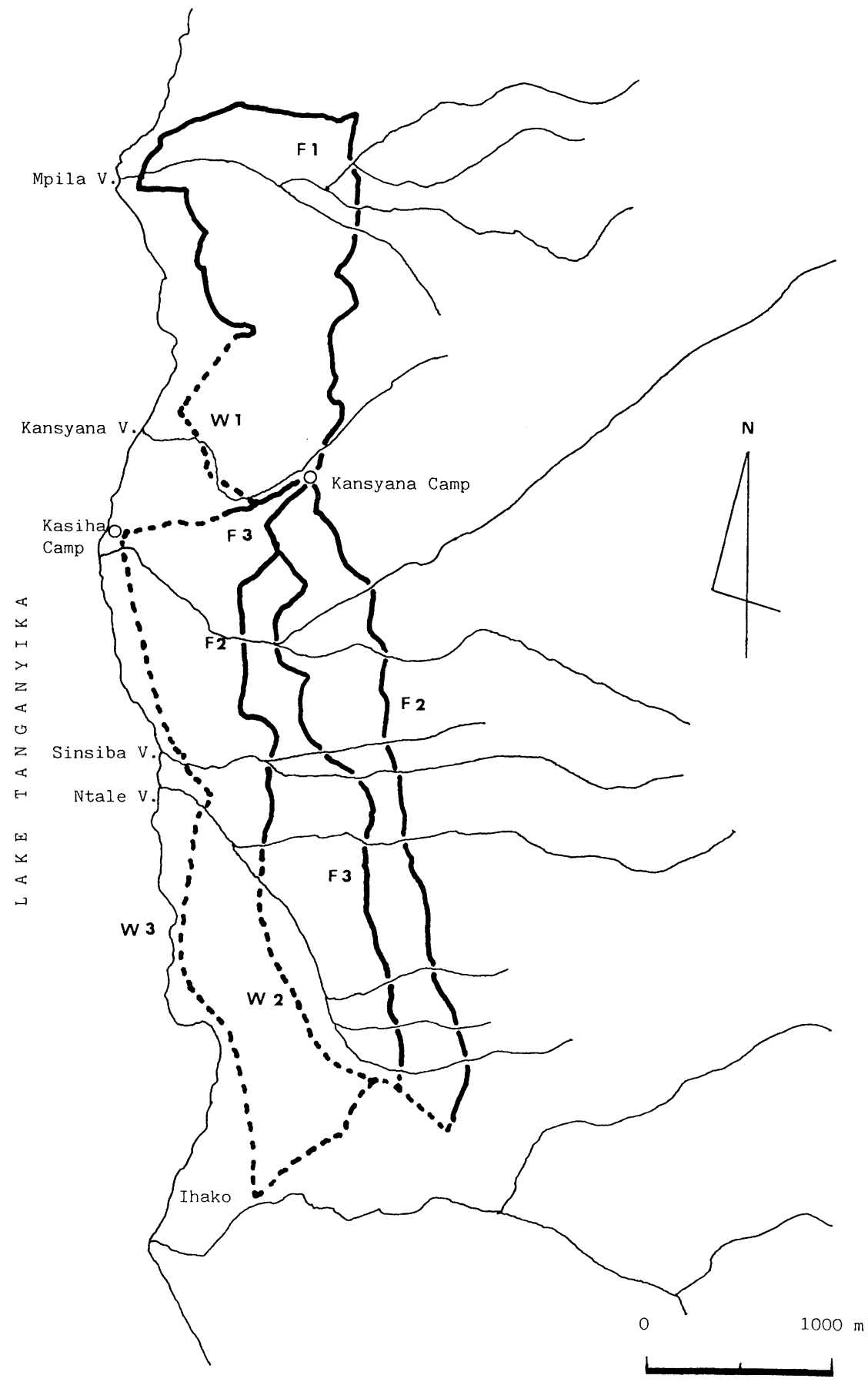

Figure 1 A map showing the Kasoje area in the Mahale Mountains National Park, Tanzania: the study area and the three census routes (CR1-CR3). Respective routes consist of forest (F1-F3) and woodland (W1-W3). 
Forest was defined as semi-deciduous ( $=$ semi-evergreen) vegetation characterized by continuous multi-layered canopy, that is, forest with closed canopy, or by discontinuous canopy of high trees (> about $20 \mathrm{~m}$ ) with dense shrub, woody vine, herb, or grass species similar to those of the forest with closed canopy, that is, secondary forest on abandoned farmland. Woodland was defined as deciduous vegetation characterized by open or continuous but single-layered canopy accompanying fairly open ground cover of grasses, etc. It also included various seral stages of secondary succession. For description of the study area in more detail, see Nishida (1972), Nishida and Uehara (1981), Collins and McGrew (1988) and Nishida (1990).

Of the trail networks used for chimpanzee research, we selected three census routes (CR1 - CR3: Figure 1). On non-census days in the early stages of Period II, the length of each route was measured with a $50 \mathrm{~m}$ rope and characteristics of vegetation along the routes were noted. Then the vegetation was classed forest (F) or woodland (W); six census subunits were distinguished as a result (F1 - F3 and W1 - W3 in Figure 1). While measuring the route distances, S. U. trained himself from time to time to estimate distances up to $50 \mathrm{~m}$ of various objects on the route. In Period I, H. I. restricted his maximum estimation by eye to $30 \mathrm{~m}$. Regrettably, marginal errors in the distance estimation were not systematically recorded in both periods.

Censusing was done by recording encounters (mainly by sighting: see below) with each animal species along each route. In Period I, censusing started between 08:29 and 10:03 hrs. and was done five times for CR1 (twice in the dry and three times in the rainy season), six times for CR2 (four times in the dry and twice in the rainy season) and seven times for CR3 (four times in the dry and three times in the rainy season), totaling 18 census days. In Period II, censusing began between 06:40 and 08:50 hrs. and was done eight times for each route, totaling 24 census days: all censusing done in the rainy season between late October and early December. The mean start times (hrs. \pm S.D. in min) for the three circuits were as follows: 08:49 \pm 12 in Period I and 07:56 \pm 47 in Period II for CR1, 08:59 \pm 13 in Period I and 07:45 \pm 56 in Period II for CR2, and 09:04 \pm 27 in Period I and 07:43 \pm 52 in Period II for CR3. Censusing was done once per day and no censusing was done on rainy days. For each census route, successive surveys were done in opposite directions.

Simplified methods of data collection were used in this study (cf. Burnham and others, 1980; Whitesides and others, 1988; White, 1994) because of good visibility in general at Kasoje, except for some parts of the dense forest floor (for example, sighting of blue duikers) and relatively flat terrain of the present census area except for the northern circuit (CR1). Some infrequent detection data from the density estimation were excluded in the analysis (see below).

In Period I, censusing was restricted to record primate species while in Period II, all mammals seen were censused. We walked slowly and quietly with a Tanzanian assistant or alone along the route at a speed of $1.4-1.9 \mathrm{~km}$ per hour, stopping periodically to watch and to listen for animals. Upon detecting a group or individual, up to about 15 minutes were spent recording data, and occasionally we moved in reverse direction in order to get 
a better view. Encounter point along the route, detection method, time, behavior, distance from the observer, and perpendicular distance from the route were recorded for the first individual of each species seen and, in the case of gregarious species, the perpendicular distance of the nearest individual from the route was also noted. All distances were estimated by eye and then and there horizontal distances were recorded as well. Horizontal, perpendicular distances from the route were used in the following analysis.

The number and age-sex classes of all animals seen were noted. Other individuals estimated to be present were recorded as well. When more than one species were present, data were collected for each species. Any other species recognized but not seen (for example, heard, usually by their alarm calls) were also noted. All noises produced by unseen fleeing animals through the undergrowth (= runaway treads on the ground) were also recorded in Period II.

For primate groups, a circle was assumed for their spatial spread (for example, Whitesides and others, 1988). Primates were considered to be in polyspecific associations if they were sighted side by side or the spread of one group was judged to overlap with that of another. Solitary monkeys were noted independently. For warthog (Phacochoerus aethiopicus), group spread was omitted, as their groups were compact and small in size (see below).

Thirteen species of mammals were noted during the census and five other species were seen on other non-census days in Period II (Appendix 1). Although at least two arboreal species of large squirrels (giant forest squirrels, Protoxerus stangeri, and red-legged sun squirrels, Heliosciurus rufobrachium) are sympatric at Mahale (Nishida and Uehara, 1983; Nishida, 1990), it is often hard to identify them in the field: they are treated together as "forest squirrels" in this report. Density is independently calculated only for those species observed at least three times in each census subunit during the census. Data on eight species in at least one census subunit have been collected for density estimation, that is, red-tailed monkey (Cercopithecus ascanius), blue monkey (C. mitis), yellow baboon (Papio cynocephalus), red colobus monkey, warthog, bushbuck (Tragelaphus scriptus), blue duiker, and forest squirrels. Vervet monkeys (Cercopithecs aethiops) are referred to for their diachronic change in distribution.

\section{Results}

\section{Length and Vegetation of the Census Routes}

Lengths of the three census routes as well as those of respective vegetation types are shown in Table 1. The distance of CR2 $(\mathrm{F} 2+\mathrm{W} 2)$ was measured twice and a disparity of at most one meter in every $500 \mathrm{~m}$ was noted. Small patches of forest or woodland extending less than $300 \mathrm{~m}$ in length and sandwiched between the opposite vegetation type were disregarded. The total length of forest vegetation along the three census routes is about twice as long as that of woodland ( $65 \%$ vs. $35 \%$ : Table 1$)$. The total length actually censused in Period I was $168,392 \mathrm{~m}$ consisting of $106,135 \mathrm{~m}$ in forest $(63 \%)$ and $62,257 \mathrm{~m}$ in woodland $(37 \%)$, while that in Period II was $220,128 \mathrm{~m}(27,516 \mathrm{~m} \times 8)$. 
Table 1 Length and vegetation types of the three census routes (CR1-CR3)

\begin{tabular}{|c|c|c|c|c|}
\hline Vegetation & CR1 & CR2 & CR3 & Total \\
\hline Forest & $6265 \mathrm{~m}$ (F1: 82.8\%) & $6950 \mathrm{~m}(\mathrm{~F} 2: 76.5 \%)$ & $4730 \mathrm{~m}(\mathrm{~F} 3: 43.6 \%)$ & $17945 \mathrm{~m}(65.2 \%)$ \\
\hline Woodland & (W1: 17.2) & (W2: 23.5) & $6131 \quad$ (W3: 56.4) & $(34.8)$ \\
\hline Total & 7565 & 9090 & 10861 & 27516 \\
\hline
\end{tabular}

\section{Sample Width and Group Spread for Density Estimate}

Sample width for the three species of terrestrial ungulates, arboreal forest squirrels, and runaway treads was taken as the distances at which the detectability of respective animals declined abruptly. Thus the width sampled on one side of the route was $20 \mathrm{~m}$ for bushbucks and warthogs (for example, bushbuck in Figure 2) and $10 \mathrm{~m}$ for blue duikers, forest squirrels, and runaway treads (for example, blue duiker in Figure 3).

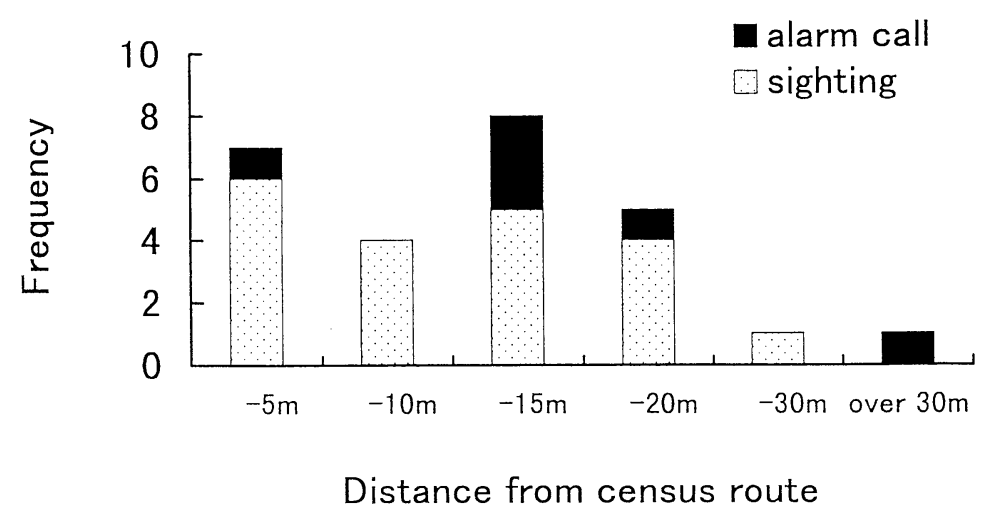

Figure 2 Detection frequency by perpendicular distance of bushbucks from census routes.

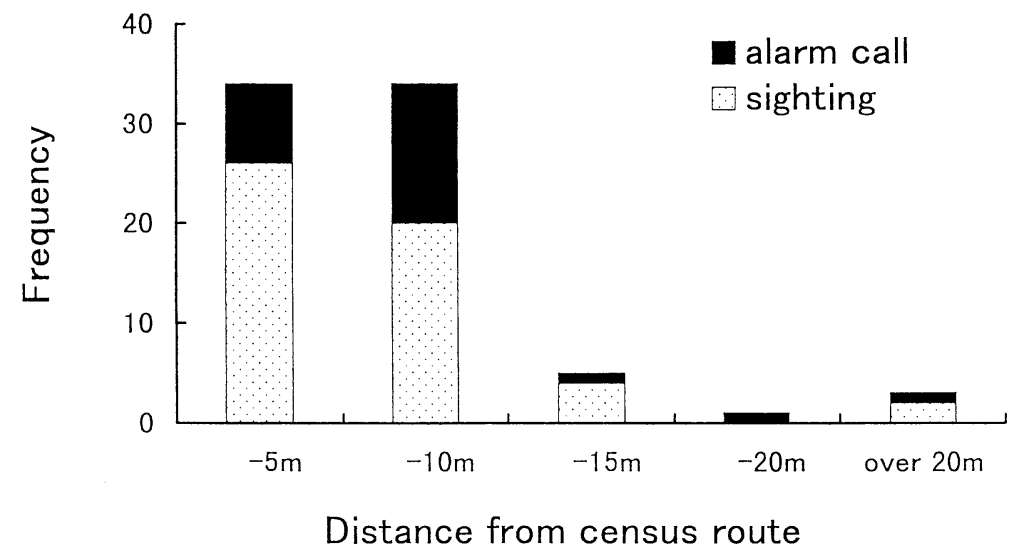

Figure 3 Detection frequency by perpendicular distance of blue duikers from census routes. 
The width sampled on one side of the route was taken as $30 \mathrm{~m}$ in Period I and $50 \mathrm{~m}$ in Period II (= the maximum distances estimated by eye) for the nearest individuals of the four species of gregarious monkeys, because such fall-off in the distance of group detectability was not clear for them (for example, Period II: Figures 4, 5, 6, and 7). This means that the sample width on one side is regarded as $50 \mathrm{~m}$ (or $30 \mathrm{~m}$ in Period I) plus a species-typical mean radius of spatial spread, as circles are assumed for the primate groups. If we further assume uniform distribution of individual monkeys within a circle of the group spread, the histogram of $\leqq 10 \mathrm{~m}$ may include all those cases when the center of a monkey group is located between $0 \mathrm{~m}$ and $(10+\mathrm{r}) \mathrm{m}$ from the census route ( $\mathrm{r}$ : the radius of group spread) (Figures 4,6 , and 7 ).

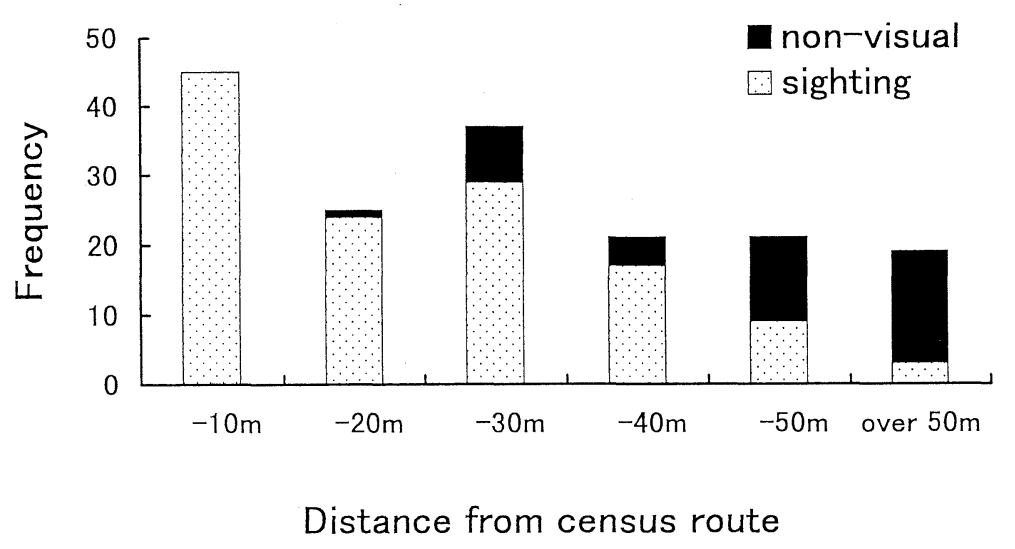

Figure 4 Detection frequency by perpendicular distance of the nearest individuals in red-tailed monkey groups from census routes in Period II. Distances were not recorded in five additional cases $(\leqq 50 \mathrm{~m})$.

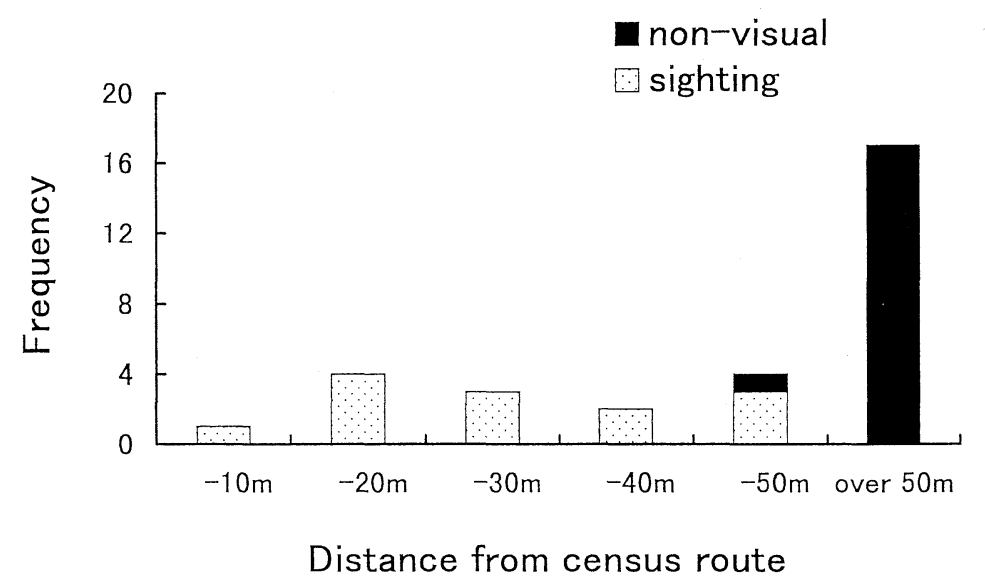

Figure 5 Detection frequency by perpendicular distance of the nearest individuals in blue monkey groups from census routes in Period II. Distance was not recorded in one additional case $(\leqq 50 \mathrm{~m})$. The majority of the histogram of $>50 \mathrm{~m}$ indicates loud calls of adult males from unknown distances. 


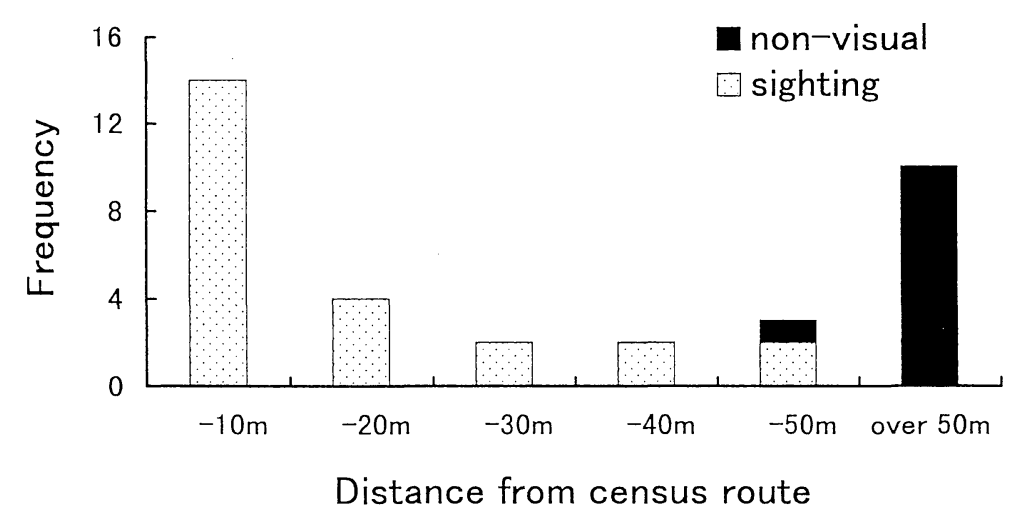

Figure 6 Detection frequency by perpendicular distance of the nearest individuals in yellow baboon groups from census routes in Period II. The majority of the histogram of $>50 \mathrm{~m}$ indicates squabbling vocalization from unknown distances.

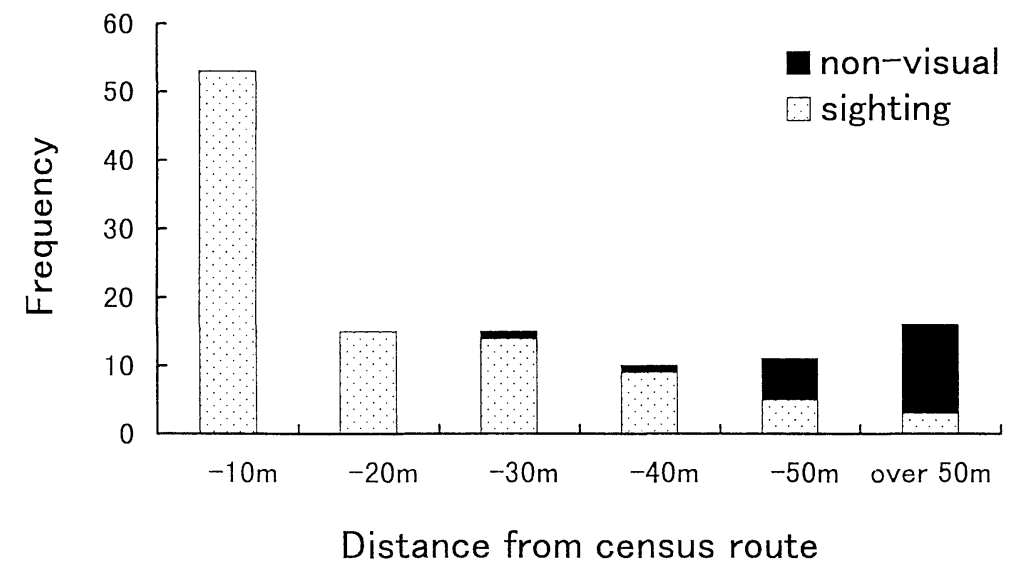

Figure 7 Detection frequency by perpendicular distance of the nearest individuals in red colobus monkey groups from census routes in Period II. Distances were not recorded in five additional cases $(\leqq 50 \mathrm{~m})$.

Accordingly, we can estimate the mean radius of each species' spread from the data in Period II (except for the blue monkey in Figure 5: see below) by the following approximation:

$$
\mathrm{n}_{1} / \mathrm{n}_{2-5} \doteqdot(10+\mathrm{r}) / 10
$$

or equivalently,

$$
\mathrm{r} \fallingdotseq 10\left\{\left(\mathrm{n}_{1} / \mathrm{n}_{2-5}\right)-1\right\}
$$

where $n_{1}$ is the number of the nearest individuals observed $\leqq 10 \mathrm{~m}$ from the census route while $\mathrm{n}_{2-5}$ represents the mean number of the nearest individuals observed in each $10 \mathrm{~m}$ 
width between $\leqq 20 \mathrm{~m}$ and $\leqq 50 \mathrm{~m}$ from the census route. Thus the mean radii of group spread for the three monkey species have been estimated as follows: $10 \mathrm{~m}$ for red-tailed monkey $\left(n_{1} / n_{2-5}=1.8\right.$ : Figure 4$), 40 \mathrm{~m}$ for yellow baboon $\left(n_{1} / n_{2-5}=5.1\right.$ : Figure 6$)$, and $30 \mathrm{~m}$ for red colobus monkey $\left(\mathrm{n}_{1} / \mathrm{n}_{2-5}=4.2\right.$ : Figure 7$)$.

The same approximation could not be applied to blue monkeys (Figure 5): they were the most unhabituated species among the four monkey species at Kasoje, always keeping the observers at some distance (personal observations by S. U. and H. I.). Moreover, they were seen only infrequently during the census, although the loud vocalization of adult males from a distance was often heard (Figure 5). Since the mean group size of blue monkeys seems similar to that of red-tailed monkeys (see below), the mean radius of their group spread is also regarded as $10 \mathrm{~m}$.

In sum, the sample width on one side of the route for their density estimate is regarded as $40 \mathrm{~m}$ in Period I and $60 \mathrm{~m}$ in Period II for red-tailed monkeys, $60 \mathrm{~m}$ in Period II for blue monkeys, $70 \mathrm{~m}$ in Period I and $90 \mathrm{~m}$ in Period II for yellow baboons, and $60 \mathrm{~m}$ in Period I and $80 \mathrm{~m}$ in Period II for red colobus monkeys.

\section{Frequency of Encounter and Habitat Preference}

Tables $2 \mathrm{a}$ and $2 \mathrm{~b}$ respectively show frequencies of encounter with the three species of monkeys in Period I and eight species of mammals and unknown runaway treads in Period II within the respective sample widths during the census, although the frequency of encounter with unknown treads is not calculated independently in each census subunit. Blue monkey groups are not included in Table 2a because they were seen only twice in Period I (both in the forest). The same groups or animals were never counted twice at or around sharp curves of the census routes.

Based on the proportion of forest/woodland length along the census routes (65/35) and the encounter frequencies with each species during the census, habitat preference of the eight species has been suggested: red-tailed monkeys, blue monkeys, red colobus monkeys, blue duikers and forest squirrels were seen more often in the forest while yellow baboons,

Table 2a Frequency of encounter with three species of monkeys (mean per day \pm S.D.) in Period I (August-December, 1995)

\begin{tabular}{lllllr}
\hline Species & Vegetation & CR1 (n) & CR2 (n) & CR3 (n) & N \\
\hline Red-tailed monkey group $^{1)}$ & Forest & $-(2)$ & $2.83 \pm 1.9(17)$ & $2.43 \pm 1.7(17)$ & 36 \\
& Woodland & $-(1)$ & $0.67 \pm 0.8(4)$ & $1.29 \pm 1.0(9)$ & 14 \\
Yellow baboon group $^{2)}$ & Forest & 0 & $-(1)$ & 0 & 0 \\
& Woodland & $-(1)$ & $0.5 \pm 1.2(3)$ & $1.71 \pm 1.0(12)$ & 16 \\
\multirow{2}{*}{ Red colobus group $^{3)}$} & Forest & $2.4 \pm 1.1(12)$ & $3.33 \pm 0.8(20)$ & $1.43 \pm 1.0(10)$ & 42 \\
& Woodland & $-(2)$ & $0.5 \pm 0.8(3)$ & $-(2)$ & 7 \\
\hline
\end{tabular}

$\mathrm{n}$ : Total number of encounters in each census subunit. -: Frequency of encounter is not indicated, as the species was observed less than three times in each census subunit. 1) Sample width $=80 \mathrm{~m}$,

2) Sample width $=140 \mathrm{~m}, 3$ ) Sample width $=120 \mathrm{~m}$. 
Table 2b Frequency of encounter with five species of gregarious and three species of non-gregarious mammals (mean per day \pm S.D.) as well as those with fleeing unknown treads in Period II (October-December, 1996)

\begin{tabular}{|c|c|c|c|c|c|}
\hline Species & Vegetation & CR1 (n) & CR2 (n) & CR3 (n) & $\mathrm{N}$ \\
\hline \multirow[t]{2}{*}{ Red-tailed monkey group ${ }^{1)}$} & Forest & $5.63 \pm 1.3(45)$ & $5.63 \pm 2.7(45)$ & $3.63 \pm 0.7(29)$ & 119 \\
\hline & Woodland & $0.88 \pm 0.8(7)$ & $0.63 \pm 0.7(5)$ & $2.88 \pm 2.1(23)$ & 35 \\
\hline \multirow[t]{2}{*}{ Blue monkey group ${ }^{1)}$} & Forest & $0.75 \pm 0.8(6)$ & $0.75 \pm 0.4(6)$ & $0.38 \pm 0.7$ & 15 \\
\hline & Woodland & 0 & 0 & 0 & 0 \\
\hline \multirow[t]{2}{*}{ Yellow baboon group ${ }^{2)}$} & Forest & $0.38 \pm 0.5$ & 0 & $-(1)$ & 4 \\
\hline & Woodland & $0.63 \pm 0.7(5)$ & $-(1)$ & $1.88 \pm 0.9(15)$ & 21 \\
\hline \multirow[t]{2}{*}{ Red colobus group ${ }^{3)}$} & Forest & $4.38 \pm 0.9(35)$ & $4.5 \pm 1.9(36)$ & $3.25 \pm 1.0(26)$ & 97 \\
\hline & Woodland & $0.63 \pm 0.7$ & $0.5 \pm 0.7$ & $0.38 \pm 0.5$ & 12 \\
\hline \multirow[t]{2}{*}{ Warthog group ${ }^{4) 5)}$} & Forest & $-(1)$ & 0 & 0 & 1 \\
\hline & Woodland & 0 & - (1) & $1.63 \pm 1.5(13)$ & 14 \\
\hline \multirow[t]{2}{*}{ Bushbuck $^{4)}$} & Forest & $-(2)$ & 0 & 0 & 2 \\
\hline & Woodland & $0.38 \pm 0.7$ & $0.5 \pm 0.7$ & $1.88 \pm 1.8(15)$ & 22 \\
\hline \multirow[t]{2}{*}{ Blue duiker ${ }^{6)}$} & Forest & $2.38 \pm 1.4(18)$ & $3.13 \pm 1.3(25)$ & $1.63 \pm 1.0(13)$ & 56 \\
\hline & Woodland & $-(1)$ & $0.63 \pm 0.5(5)$ & $0.75 \pm 0.4(6)$ & 12 \\
\hline \multirow[t]{2}{*}{ Forest squirrel $^{6)}$} & Forest & $0.38 \pm 0.5(3)$ & $0.38 \pm 0.7$ & $0.88 \pm 0.8(7)$ & 13 \\
\hline & Woodland & $-(1)$ & $-(1)$ & $-(1)$ & 3 \\
\hline \multirow[t]{2}{*}{ Unknown tread ${ }^{6)}$} & Forest & & & & 45 \\
\hline & Woodland & & & & 15 \\
\hline
\end{tabular}

$\mathrm{n}$ : Total number of encounters in each census subunit. -: Frequency of encounter is not indicated, as the species was observed less than three times in each census subunit. 1) Sample width $=120 \mathrm{~m}$, 2) Sample width $=180 \mathrm{~m}, 3$ ) Sample width $=160 \mathrm{~m}, 4$ ) Sample width $=40 \mathrm{~m}, 5$ ) Warthog groups include solitary animals, 6) Sample width $=20 \mathrm{~m}$.

warthogs, and bushbucks were detected more frequently in the woodland (Tables 2a and $2 b)$. However, the differences are significant only on two species and nearly significant on another species (binomial test using the pooled data of the first census records of each census route at the beginning of the rainy season of respective periods: red-tailed monkey in Period I, $\mathrm{N}=12, \mathrm{p}=0.042$; bushbuck in Period II, $\mathrm{N}=5, \mathrm{p}=0.005$; red colobus monkey in Period $\mathrm{I}, \mathrm{N}=6, \mathrm{p}=0.075$ and P.eriod II, $\mathrm{N}=19, \mathrm{p}=0.059$ ).

\section{Group Density}

Polyspecific associations among the four monkey species, particularly among the three arboreal species, are common at Mahale (also see Nishida, 1972). Responses by the monkeys to alarm calls of the terrestrial ungulates (blue duiker or bushbuck) and vice versa were sometimes noted as well. However, each species is treated independently in the following analysis.

Group densities (per $\mathrm{km}^{2}$ ) of the three primate species in Period I and those of the five gregarious mammals in Period II are shown in Tables $3 a$ and $3 b$, respectively. Note that warthog groups include solitary individuals while monkey groups do not (see below). 
Table 3a Group densities per $\mathrm{km}^{2}$ of the three species of monkeys in Period I (August-December, 1995)

\begin{tabular}{lllccc}
\hline Species & Vegetation & CR1 & CR2 & CR3 & Mean $^{1)}$ \\
\hline Red-tailed monkey & Forest & - & 5.1 & 6.4 & 4.2 \\
& Woodland & - & 3.9 & 2.6 & 2.8 \\
Yellow baboon & Forest & 0 & - & 0 & - \\
& Woodland & - & 1.7 & 2.0 & 1.8 \\
\multirow{3}{*}{ Red colobus } & Forest & 3.2 & 4.0 & 2.5 & 3.3 \\
& Woodland & - & 1.9 & - & 0.9 \\
\hline
\end{tabular}

-: Density is not calculated, as the species was observed less than three times in each census subunit. 1) Mean densities were calculated from the total number of encounters $(\mathrm{N})$ in Table $2 \mathrm{a}$ and the area covered during the census.

Table 3b Group densities per $\mathrm{km}^{2}$ of the five species of gregarious mammals in Period II (October-December, 1996)

\begin{tabular}{llllll}
\hline Species & Vegetation & CR1 & CR2 & CR3 & Mean $^{1)}$ \\
\hline Red-tailed monkey & Forest & 7.5 & 6.8 & 6.4 & 6.9 \\
& Woodland & 5.6 & 2.4 & 3.9 & 3.8 \\
Blue monkey & Forest & 1.0 & 0.9 & 0.7 & 0.9 \\
& Woodland & 0 & 0 & 0 & 0 \\
Yellow baboon & Forest & 0.3 & 0 & - & 0.2 \\
\multirow{3}{*}{ Red colobus } & Woodland & 2.7 & - & 1.7 & 1.5 \\
& Forest & 4.4 & 4.0 & 4.3 & 4.2 \\
Warthog & Woodland & 3.0 & 1.5 & 0.4 & 1.0 \\
& Forest & - & 0 & 0 & - \\
& Woodland & 0 & - & 6.6 & 4.6 \\
\hline
\end{tabular}

-: Density is not calculated, as the species was observed less than three times in each census subunit. 1) Mean densities were calculated from the total number of encounters ( $\mathrm{N}$ ) in Table $2 \mathrm{~b}$ and the area covered during the census, 2) Warthog groups include solitary animals.

\section{Group Size and Solitary Animals}

We could not collect sufficient data to calculate mean group sizes of the four gregarious monkey species during the study period. Based on some group counts of the four species in Period II (Table 4), the following figures are used as respective group sizes for the calculation of individual densities: 12 for red-tailed monkey, 10 for blue monkey, 40 for yellow baboon, and 30 for red colobus monkey.

Previous estimates in the study area resemble these. In the late 1960s, Nishida (1969) stated that groups of red-tailed monkeys appeared to consist of 10-20 individuals, with the largest group seen being 14 . He also described that, although only 3-5 monkeys were seen together on many occasions, blue monkey groups containing 10 or more animals were 
Table 4 Group sizes of the four species of monkeys observed in Period II (October - December, 1996)

\begin{tabular}{lcc}
\hline Species & Census subunit & Group size \\
\hline Red-tailed monkey & F2 & $>11$ \\
& F3 & $>8$ \\
W3 & W3 & 15 \\
Blue monkey & F2 & $>11$ \\
Yellow baboon & F2 & $>6$ \\
& W2 & $>6$ \\
Wed colobus & W3 & $>39$ \\
& W3 & $>26$ \\
& W3 & $>32$ \\
W3 & $>25$ \\
& F1 & $>26$ \\
& F1 & $>20$ \\
& F2 & $>23$ \\
F2 & 28 \\
& F2 & $>26$ \\
& F3 & 32 \\
\hline
\end{tabular}

observed three times, the largest one including 18. For yellow baboons, Nishida stated that they never occurred in the forest habitat and their groups near Kasoje were small in size, consisting of fewer than 13 individuals. In another paper (Nishida, 1972), he reported that two study groups of red colobus monkeys appeared to number about 40 each in 1969. Hasegawa and others (1980) noted that the size of a baboon group, which utilized the lakeshore area in the 1970s, was about 40. In 1979, Takahata (1981) showed that the mean size of five red-tailed monkey groups was $8.4 \pm 1.3$ (range: 7-10). He also estimated that an average group of blue monkeys contained 10-20 individuals, while that of red colobus consisted of about 40 animals. Recently, Ihobe (unpublished data) clarified in his intensive socio-ecological investigation of red colobus monkeys in 1995 and 1998 that the study group consisted of 30 individuals and utilized an area of about 25 ha.

During the census, solitary red-tailed monkeys were observed five times in Period I and 10 times in Period II and those of red colobus monkeys three times in Period I and twice in Period II, while a solitary yellow baboon was seen only once in Period II. No solitary blue monkey was detected on census days. Solitary monkeys are excluded from the present calculation of individual density as the average group sizes were only roughly estimated.

Warthogs were seen alone or in groups consisting of up to nine individuals and their group composition was clarified on 30 occasions throughout Period II. When dependent offspring were excluded, however, the maximum group size of the warthogs at Kasoje was only 5, and the mean, median, and modal size (including solitary animals) become 2.2, 2, and 2, respectively. Accordingly, the following individual density of warthogs has been calculated 
on the assumption that an average group contains two independent animals.

Pairs of bushbucks, blue duikers, and forest squirrels, most of which were a mother with her offspring, were sometimes seen on non-census days as well as outside the sample widths during the census in Period II. However, the following calculation of individual density does not take such pairs into consideration, which means that dependent animals are excluded from the present estimation as well.

\section{Individual Density}

Individual densities (per $\mathrm{km}^{2}$ ) of the three species of monkeys in Period I and the eight species of mammals and fleeing unknown treads in Period II are shown, respectively, in Tables $5 \mathrm{a}$ and $5 \mathrm{~b}$. The area actually covered in the present census on the basis of meandering routes is narrower than that measured by the linear (straight) transect method, which tends to overestimate the densities of all subject species. On the other hand, the densities of terrestrial ungulates and forest squirrels have been underestimated by some factors in this study. Firstly, fleeing unidentified treads (Table 5b) surely include those of terrestrial birds, small mammals (such as chequered elephant shrew, Rhynchocyon cirnei), blue duiker, bushbuck, warthog, and bushpig (personal impression in Period II). Secondly, dependent individuals of warthog, blue duiker, bushbuck, and forest squirrels are excluded from the present estimation. Finally, it is possible that during the census forest squirrels have been missed more frequently than other species, as they are smaller solitary arboreal animals.

Except for the yellow baboon, densities in Period I tend to be lower than those in Period II (Tables 5a and 5b). This may have been caused in part by the difference in sample widths. In Period I, unhabituated arboreal species or groups of monkeys may have been missed more frequently from censusing owing to the narrower sample width (for example, see Figure 5 for detection distance of the blue monkey in Period II). Although still speculative, earlier start times of censusing in Period II seem to be responsible as well. Observations in Period II may have been more successful in detecting arboreal monkeys

Table 5a Individual densities per $\mathrm{km}^{2}$ of the three species of monkeys in Period I (August-December, 1995)

\begin{tabular}{lllllc}
\hline Species & Vegetation & CR1 & CR2 & CR3 & Mean $^{1)}$ \\
\hline Red-tailed monkey & Forest & - & 61.2 & 76.8 & 50.4 \\
& Woodland & - & 46.8 & 31.2 & 33.6 \\
Yellow baboon & Forest & 0 & - & 0 & - \\
\multirow{4}{*}{ Red colobus } & Woodland & - & 68 & 80 & 72 \\
& Forest & 96 & 120 & 75 & 99 \\
& Woodland & - & 57 & - & 27 \\
\hline
\end{tabular}

1) Mean densities were calculated from the mean group densities in Table $3 a$ and the group sizes (see text). 
Table 5b Individual densities per $\mathrm{km}^{2}$ of the eight species of mammals and fleeing unknown treads in Period II (October-December, 1996)

\begin{tabular}{|c|c|c|c|c|c|}
\hline Species & Vegetation & CR1 & CR2 & CR3 & Mean $^{1)}$ \\
\hline \multirow[t]{2}{*}{ Red-tailed monkey } & Forest & 90 & 81.6 & 76.8 & 82.8 \\
\hline & Woodland & 67.2 & 28.8 & 46.8 & 45.6 \\
\hline \multirow[t]{2}{*}{ Blue monkey } & Forest & 10 & 9 & 7 & 9 \\
\hline & Woodland & 0 & 0 & 0 & 0 \\
\hline \multirow[t]{2}{*}{ Yellow baboon } & Forest & 12 & 0 & - & 6.2 \\
\hline & Woodland & 108 & - & 68 & 60 \\
\hline \multirow[t]{2}{*}{ Red colobus } & Forest & 132 & 120 & 129 & 126 \\
\hline & Woodland & 90 & 45 & 11.5 & 29.4 \\
\hline \multirow[t]{2}{*}{ Warthog 2$)$} & Forest & - & 0 & 0 & - \\
\hline & Woodland & 0 & - & 13.2 & 9.1 \\
\hline \multirow[t]{2}{*}{ Bushbuck $^{2)}$} & Forest & - & 0 & 0 & - \\
\hline & Woodland & 7.2 & 5.8 & 7.6 & 7.2 \\
\hline \multirow[t]{2}{*}{ Blue duiker ${ }^{2)}$} & Forest & 19.6 & 22.5 & 17.2 & 19.5 \\
\hline & Woodland & - & 14.6 & 6.1 & 7.8 \\
\hline \multirow[t]{2}{*}{ Forest squirrel $^{2)}$} & Forest & 3.0 & 2.7 & 9.2 & 4.5 \\
\hline & Woodland & - & - & - & - \\
\hline \multirow[t]{2}{*}{ Unknown tread } & Forest & & & & 15.7 \\
\hline & Woodland & & & & 9.8 \\
\hline
\end{tabular}

1) Mean densities were calculated from the mean group densities in Table $3 b$ and the group sizes (see text) for the gregarious species and from the total number of encounters $(\mathrm{N})$ in Table $2 \mathrm{~b}$ and the area covered during the census for the solitary species, 2) Excluding dependent individuals.

due to their conspicuous morning activities such as feeding or moving.

In Period II, at least two, possibly as many as three, different groups of yellow baboons were observed within the narrow census subunit W1 (Table 2b). In Period I, however, they were seen only once in the same subunit during the census (Table 2a). Similarly, red-tailed monkeys were commonly seen along CR1 in Period II but only infrequently in Period I (Tables $2 \mathrm{a}$ and $2 \mathrm{~b}$ ). Although the reason for such inter-annual fluctuation is unclear, seasonal and inter-annual changes in fruit availability may have something to do with the difference in some cases; censusing was done in the dry season only in Period I.

Among the study mammals of Kasoje, red-tailed monkeys, yellow baboons, warthogs, and forest squirrels have been observed to feed on fruits or fallen seeds of the oil palm (Elaeis guineensis) (Uehara, unpublished data). Although groves of this cultivated tree species were common in the northern part of W2 as well as along W3, the fruits or fallen seeds were plentiful only along the latter in Period II. Contrasting densities of the red-tailed monkey, the yellow baboon, and the warthog between W2 and W3 in Period II (Table $2 \mathrm{~b}$ and $5 \mathrm{~b}$ ) may have been caused at least partly by the difference in availability of the oil palm crops. On the other hand, contrasting densities of the other two forest species, the red colobus (both in Period I and II) and the blue duiker (in Period II), between W2 
and W3 (Tables 2a, 2b and 5b) appear to reflect that the latter census subunit is more distantly located from the inland forest (Figure 1).

Although categorized as woodland, W1 was a mosaic of the two vegetation types as it crossed the downstream area of the Kansyana valley several times (Figure 1). It is likely that this explains the moderate densities of the two common forest monkeys, the red-tailed and the red colobus, along W1 in Period II (Table 5b).

\section{Discussion}

\section{Diachronic Changes of Distribution and Abundance in Relation to Human Interference} and Secondary Succession

Although Mahale became the eleventh national park of Tanzania in 1985, as early as in 1974, most villagers had already moved out of the Kasoje areas following a government edict; farming and burning were banned and hunting was prohibited. The wild animal population in general appears to have gradually increased in number from then onward as secondary succession of vegetation or forest colonization progressed, although drastic shift of succession between woodland and forest has not been observed.

In the late 1960s, Nishida (1969) stated that red-tailed monkeys seemed to be the most ubiquitous monkeys at Kasoje. In another report (Nishida, 1972), he estimated that the population density of red colobus at Kasoje was 2-2.7 groups or 80-100 monkeys per km² within a narrow strip of relatively undisturbed forest. In 1979, Takahata (1981) reported that the population density of red-tailed monkeys was 3.8 groups or about 40 animals per $\mathrm{km}^{2}$ in the forest between the Mpila valley and the Sinsiba valley (Figure 1) and the group density of red colobus was 1.7 per km$~^{2}$ in the same area. The density of red colobus monkeys in 1979 must have been underestimated, as Takahata (1981: Figure 4) estimated an area much wider than that clarified by Ihobe (unpublished data) for their group range. Although no systematic census has been taken before, these results suggest a gradual population increase of the red-tailed monkey and the red colobus.

It is difficult to show definite changes in abundance by anecdotal evidence, but other qualitative evidence of diachronic change in distribution of three particular species has occurred since the 1970s. Warthogs seem to have immigrated permanently into the study area: they were observed only very rarely before the 1980s but they have recently become common in open vegetation of Kasoje (Nishida and Uehara, 1983). They are seen these days even in colonizing forest where groves of oil palms in the former settlements remain.

Yellow baboons have increasingly expanded their distribution as well toward inland areas. Before the 1980s baboons at Kasoje used only open areas in a narrow strip along Lake Tanganyika that chimpanzees rarely utilized (Hasegawa and others, 1980). However, they began to invade eastwards along some valleys in the 1980s and have enlarged their home ranges to include the inland forest.

Although direct interactions between baboons and chimpanzees still appear to have occurred only rarely (but see below and Nishida, 1997), indirect competition between the two species has become explicit; they have been observed to consume the same food items 
in the same trees at different times. For example, baboons never visited Kansyana Camp (Figure 1) before the 1990s. In 1992, they were seen for the first time to come to the camp (Uehara, unpublished data) and in October 1995, they were first seen to eat the fruit of Pseudospondias microcarpa (Nishida and others, unpublished data) which was one of the most important food patches of the chimpanzees of M Group at the camp. The increasing use of the high-altitude areas by the chimpanzees (Nishida and others, unpublished data) might be caused by increasing use of the lowland areas by the baboons. It is likely that baboons' range expansion has influenced recent ranging patterns of $M$ Group in a form of exploitation competition.

In contrast, the distribution of vervet monkeys at Kasoje seems to have contracted. In the late 1960s, 3-5 vervet monkey groups were thought to live in the Kasoje area (Nishida, 1969). In the 1970s, they were not uncommon particularly along the lake shore (W3) where the human inhabitants mainly lived (Uehara, unpublished data). In 1979, a group of vervet monkeys was still present near the estuary of the Sinsiba-Ntale valleys (Takahata, 1981: Figure 3). In the present study, their density could not be estimated due to their tiny local distribution which the census failed to cover: they are still common in and around Kasiha Camp (personal observations by S. U. and H. I.) where the research staff live (Figure 1). Overall, we encountered groups of vervet monkeys only three times near Kasiha Camp during the census in W3, once in Period I and twice in Period II. Moreover, S. U. walked W3 on seven other non-census days in Period II and saw a group of vervet monkeys only once at Thako (Figure 1).

In conclusion, expansion or contraction of range utilization by the three species of mammals since the 1970 s differs from species to species. Closer monitoring to follow changes in distribution of the three species as well as of other mammals and their population densities is needed continuously in the future. It is necessary to clarify, as well, the factors affecting such diachronic fluctuations (also see below).

\section{Mammals as Prey of Chimpanzees}

Availability or abundance of potential prey in at least some cases at Mahale seems to have affected predation frequency by the chimpanzees (Nishida and Uehara, 1983; Uehara and others, 1992). Warthog piglets were seen for the first time to be captured by the chimpanzees of M Group in the 1980s. In 1997, an infant baboon was first observed to be consumed by the chimpanzees of M Group (Nakamura, 1997). In contrast, we have recently witnessed only one chimpanzee predation on vervet monkey in 1994 (Mitani, unpublished data) despite improved observation conditions in the 1980-90s, although we observed three such incidents before 1983 (Nishida and others, 1979; Takahata and others, 1984).

A total of 17 mammalian species has been confirmed as prey of chimpanzees of $\mathrm{K}$ and M Groups at Mahale (Nishida and others, 1979; Kawanaka, 1982; Hasegawa and others, 1983; Norikoshi, 1983; Takahata and others, 1984; Uehara and others, 1992; Nakamura, 1997), but more than $90 \%$ of all identified prey eaten by the chimpanzees of M Group 
between 1981 and 1990 (mainly infants or juveniles: $\mathrm{N}=115$ ) consisted of only five resident species, that is, red colobus monkey (53\%), blue duiker (20\%), bushbuck (7\%), bushpig (Potamochoerus porcus: 7\%), and red-tailed monkey (5\%) (Takahata and others, 1984; Uehara and others, 1992). Recently, the proportion of red colobus consumption has jumped up to $82 \%(\mathrm{~N}=100$, data from 1991-92 and 1993-94 inclusive: Hosaka, 1995).

In the present study, the density of bushpigs could not be estimated due to their nocturnal habits: they were seen only five times in total during the census in Period II (three times in the forest and twice in the woodland). Among the other resident terrestrial ungulates, the frequencies of predation on blue duikers and bushbucks by chimpanzees appear to correspond to some extent with their relative abundance, although their average age composition and density in the past remain unclear.

Among the resident arboreal mammals censused, the frequencies of predation on red colobus, blue monkeys, and forest squirrels by the chimpanzees also seem to reflect their relative abundance. We have seen only one case of blue monkey consumption and two episodes of squirrel eating by the chimpanzees between 1965 and 1991 (Nishida and others, 1979; Uehara and others, 1992; Huffman and Mohamedi, 1993). Note, however, that hunting at Mahale for solitary smaller mammals such as the forest squirrels may occur more often than we are aware of (Huffman and Mohamedi, 1993).

Although a selective tendency to hunt for forest monkeys is recognizable when we compare varied prey profiles of chimpanzee predation across Africa (Uehara, 1997), the chimpanzees at Mahale show a rather euryphagous feature in terms of the selectivity of prey species (Nishida, 1974; Boesch and Boesch, 1989). Except for red-tailed monkeys, another resident species and the second most abundant in the study area, the opportunistic nature of their hunting behavior appears to have been reconfirmed here on the basis of the abundance of potential prey. It should be explained in the future why chimpanzees have eaten the red-tailed monkeys only infrequently. Clearly, they were not rare species before the 1990s (Nishida, 1969; Takahata, 1981; Uehara, unpublished data). Regrettably, with respect to the hunting of Mahale chimpanzees, the frequency (= number of hunting attempts/ number of all encounters with each prey species) and success rate (= number of successful hunts/ number of all hunting attempts at each prey species) have not been systematically studied with the exception of the recent success rate of colobus hunting (Hosaka, 1995, unpublished data).

Further accumulation of observations on actual encounters between chimpanzees and their potential prey is necessary in order to clarify the prey profile, or selectivity, as well as the frequency of chimpanzee hunting at Mahale in more detail (also see Uehara, 1997). Quantitative comparisons between the frequency of chimpanzee predation and the abundance of potential prey across different populations in Africa will also be possible when similar sets of systematic data accumulates from other study sites. 


\section{Acknowledgments}

The field work was financed by the Monbusho (Japanese Ministry of Education, Science, Sports and Culture) International Scientific Research Program (07041138 to Toshisada Nishida). The Tanzania Commission for Science and Technology (COSTECH), the Serengeti Wildlife Research Institute (SWRI), the Tanzania National Parks (TANAPA), the Mahale Mountains Wildlife Research Centre (MMWRC), and the Mahale Mountains National Park (MMNP) permitted the research. Bunde Athumani, Rashidi Hawazi (Kijanga), Makelele Masayuke and Saidi Musa alternately assisted our census. Michael A. Huffman, Noriko Itoh, Kenji Kawanaka, Linda F. Marchant, William C. McGrew, Michio Nakamura, Toshisada Nishida, Kohshi Norikoshi and Hitoshi Sasaki cooperated in the field. Fumio Fukuda, Hosea Y. Kayumbo, Toshimichi Nemoto, T. Nishida and Moyo Uehara helped us in various ways for the completion of the research. Useful comments on the manuscript were provided by M. Huffman, W.C. McGrew, Naofumi Nakagawa, Hiroyuki Takasaki and T. Nishida. The preparation of this paper was financed in part by a 1997 Research Grant (Kenkyu Josei) from Sapporo University (to S. U.) and a 1997 Research Grant from Inamori Foundation (to H. I). To these people and institutions, we make grateful acknowledgement.

Appendix 1 Mammals of Kasoje in the Mahale Mountains observed in Period II of this study (October-December, 1996).

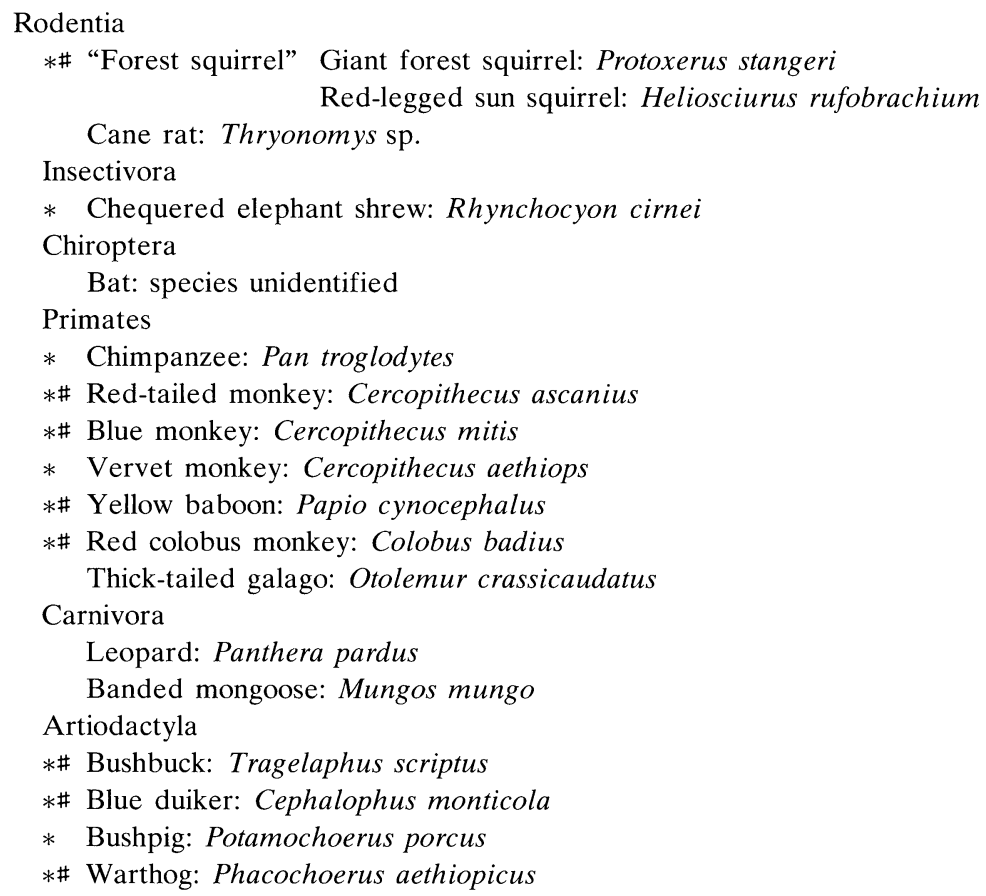

Note: $*$ indicates species seen on census days. \# indicates species whose density has been estimated in this study. 


\section{REFERENCES}

Anonymous (1980) Mahale: Study for the Proposed Mahale Mountains National Park, Final Report May 1980. The Japan International Cooperation Agency, Tokyo.

Boesch C. and Boesch H. (1989) Hunting behavior of wild chimpanzees in the Taï National Park. American Journal of Physical Anthropology, vol. 78, pp. 547-573.

Burnham K.P., Anderson D.R., and Laake J.L. (1980) Estimation of density from line transect sampling of biological populations. Wildlife Monographs, no. 72, pp. 1-202.

Collins D.A. and McGrew W.C. (1988) Habitats of three groups of chimpanzees (Pan troglodytes) in western Tanzania compared. Journal of Human Evolution, vol. 17, pp. 553-574.

Goodall J. (1986) The Chimpanzees of Gombe: Patterns of Behavior. The Belknap Press of Harvard University Press, Cambridge, Massachusetts.

Hasegawa M., Uehara S., and Nishida T. (1980) Preliminary report on the food ecology of baboons of Kasoje. Mahale Mountains Chimpanzee Research Project, Ecological Report No. 8.

Hasegawa T., Hiraiwa M., Nishida T., and Takasaki H. (1983) New evidence on scavenging behavior in wild chimpanzees. Current Anthropology, vol. 24, pp. 231-232.

Holenweg A.K., Noë R., and Schabel M. (1996) Waser's gas model applied to associations between red colobus and Diana monkeys in the Taï National Park, Ivory Coast. Folia Primatologica, vol. 67, pp. 125-136.

Hosaka K. (1995) Chimpanzee predation on red colobus in Mahale Mountains National Park, Tanzania. Anthropological Science, vol. 103, p. 106.

Huffman M.A. and Mohamedi S.K. (1993) Tool-assisted predation on a squirrel by a female chimpanzee in the Mahale Mountains, Tanzania. Primates, vol. 34, pp. 93-98. Itani J. (1977) Ethnozoology of the Batongwe. In Itani J. and Harako R. eds., “The Natural History of Man”, Yuzan-kaku, Tokyo, pp. 441-537 (in Japanese).

Kawanaka K. (1982) Further studies on predation by chimpanzees of the Mahale Mountains. Primates, vol. 23, pp. 364-384.

Nakamura M. (1997) First observed case of chimpanzee predation on yellow baboons (Papio cynocephalus) at the Mahale Mountains National Park. Pan Africa News, vol. 4, pp. 9-11.

Nishida T. (1968) The social group of wild chimpanzees in the Mahali Mountains. Primates, vol. 9, pp. 167-224.

Nishida T. (1969) Monkeys in Kasoge. Monkey, no. 105, pp. 5-15 (in Japanese).

Nishida T. (1972) A note on the ecology of the red-colobus monkeys (Colobus badius tephrosceles) living in the Mahali Mountains. Primates, vol. 13, pp. 57-64.

Nishida T. (1974) Ecology of wild chimpanzees. In Ohtsuka R., Tanaka J., and Nishida T. eds., "Human Ecology", Kyouritsu-shuppan, Tokyo, pp. 15-60 (in Japanese).

Nishida T. (1990) A quarter century of research in the Mahale Mountains: an overview. In Nishida T. ed., "The Chimpanzees of the Mahale Mountains: Sexual and Life History Strategies”, University of Tokyo Press, Tokyo, pp. 3-35. 
Nishida T. (1996) The exhibition and workshop to commemorate the 30th anniversary of chimpanzee research at Mahale. Pan Africa News, vol. 3, no. 1, pp. 1-2.

Nishida T. (1997) Baboon invasion into chimpanzee habitat. Pan Africa News, vol. 4, pp. 11-12.

Nishida T. and Uehara S. (1981) Kitongwe names of plants: a preliminary listing. African Study Monographs, vol. 1, pp. 109-131.

Nishida T. and Uehara S. (1983) Natural diet of chimpanzees (Pan troglodytes schweinfurthii): long-term record from the Mahale Mountains, Tanzania. African Study Monographs, vol. 3, pp. 109-130.

Nishida T., Uehara S., and Ramadhani N. (1979) Predatory behavior among wild chimpanzees of the Mahale Mountains. Primates, vol. 20, pp. 1-20.

Noë R. and Bshary R. (1997) The formation of red colobus-diana monkey associations under predation pressure from chimpanzees. Proceedings of the Royal Society of London, Series B, vol. 264, pp. 253-259.

Norikoshi K. (1983) Prevalent phenomenon of predation observed among wild chimpanzees of the Mahale Mountains. Journal of the Anthropological Society of Nippon, vol. 91, pp. 475-480.

Okada T., Asada N., and Kawanaka K. (1988) A result of drosophilid survey in Tanzania. African Study Monographs, vol. 8, pp. 159-163.

Stanford C.B. (1995) The influence of chimpanzee predation on group size and anti-predator behaviour in red colobus monkeys. Animal Behaviour, vol. 49, pp. 577-587.

Stanford C.B., Wallis J., Matama H., and Goodall J. (1994) Patterns of predation by chimpanzees on red colobus monkeys in Gombe National Park, 1982-1991. American Journal of Physical Anthropology, vol. 94, pp. 213-228.

Takada H. and Uehara S. (1987) Drosophilid flies (Diptera) in the Mahale Mountains National Park, Tanzania: a preliminary report. African Study Monographs, vol. 7, pp. 15-19.

Takahata Y. (1981) A preliminary report on distribution, habitat preference, and food habits of sympatric primates in the Mahale Mountains. Mahale Mountains Chimpanzee Research Project, Ecological Report No. 14a.

Takahata Y., Hasegawa T., and Nishida T. (1984) Chimpanzee predation in the Mahale Mountains from August 1979 to May 1982. International Journal of Primatology, vol. 5, pp. 213-233.

Uehara S. (1997) Predation on mammals by the chimpanzee (Pan troglodytes). Primates, vol. 38, pp. 193-214.

Uehara S., Nishida T., Hamai M., Hasegawa T., Hayaki H., Huffman M.A., Kawanaka K., Kobayashi S., Mitani J.C., Takahata Y., Takasaki H., and Tsukahara T. (1992) Characteristics of predation by the chimpanzees in the Mahale Mountains National Park, Tanzania. In Nishida T., McGrew W.C., Marler P., Pickford M., and de Waal F.B.M. eds., “Topics in Primatology, Vol. 1: Human Origins”, University of Tokyo Press, Tokyo, pp. 143-158. 
White L.J.T. (1994) Biomass of rain forest mammals in the Lopé Reserve, Gabon. Journal of Animal Ecology, vol. 63, pp. 499-512.

Whitesides G.H., Oates J.F., Green S.M., and Kluberdanz R.P. (1988) Estimating primate densities from transects in a West African rain forest: a comparison of techniques. Journal of Animal Ecology, vol. 57, pp. 345-367.

Wrangham R.W. and Bergmann Riss E. van Z. (1990) Rates of predation on mammals by Gombe chimpanzees, 1972-1975. Primates, vol. 31, pp. 157-170.

Corresponding author: Shigeo Uehara (email: uehara-s@sapporo-u.ac.jp)

Handling editor: Nishida Toshisada 